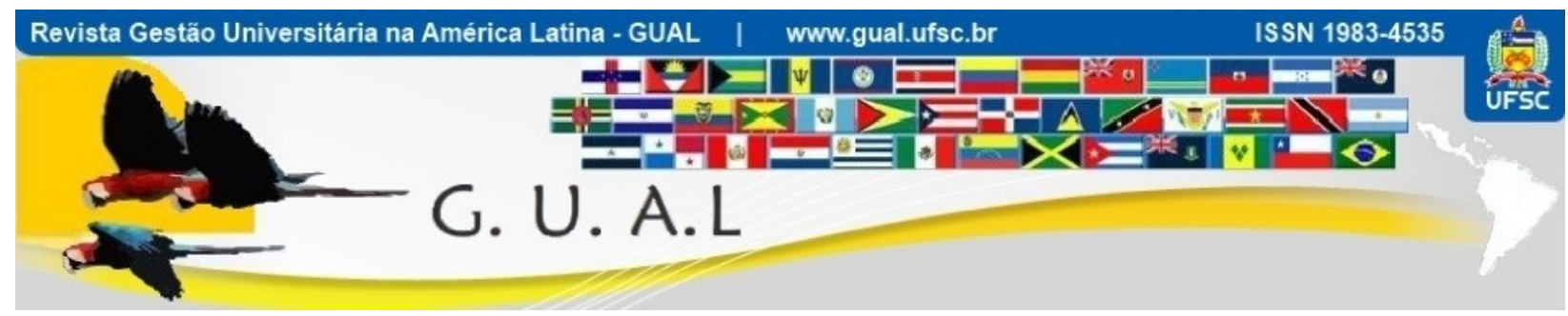

DOI: http://dx.doi.org/10.5007/1983-4535.2015v8n2p199

\title{
CAMINHOS FORMACIONAIS NA ENGENHARIA DE PRODUÇÃO: A FORMAÇÃO DOCENTE E OS RESULTADOS DO ENADE 2011
}

\section{FORMATIONAL PATHS IN PRODUCTION ENGINEERING: THE TEACHERS DEGREE AND RESULTS OF ENADE 2011}

\begin{abstract}
José André Villas Boas Mello, Doutor Centro Federal de Educação Tecnológica Celso Suckow da Fonseca - CEFET/RJ joseavbm@yahoo.com.br

Flaviane Rodrigues De Sousa, Graduada Centro Federal de Educação Tecnológica Celso Suckow da Fonseca - CEFET/RJ flaviane rs@hotmail.com
\end{abstract}

Recebido em 29/setembro/2014

Aprovado em 15/março/2015

Sistema de Avaliação: Double Blind Review

Esta obra está sob uma Licença Creative Commons Atribuição-Uso. 


\title{
RESUMO
}

O objetivo deste artigo é o de investigar se as instituições que empregam doutores, profissionais mais reflexivos, em seu quadro de docentes tendem a ter um desempenho melhor no exame nacional de desempenho estudantil (ENADE). Os dados referentes aos resultados do ENADE do grupo VI de 2011 divulgados em 2013 foram tabulados e analisados de modo a se permitir uma diferente visão do desempenho, tentando qualificar os resultados alcançados pelos segmentos de docentes: especialistas, mestres e doutores. Como resultado é possível afirmar que os cursos mais bem avaliados são os ofertados pelas instituições públicas de ensino superior. E que quando ocorre a predominância de docentes com a formação de Doutor, há a tendência de o curso ser bem avaliado.

Palavras-chave: Avaliação. ENADE. Docente.

\begin{abstract}
The aim of this article is to investigate whether the institutions that employ doctors, more reflective practitioners in its framework for teachers tend to have a better performance in the national examination of student performance (ENADE). The data relating to the results of the group VI ENADE 2011 released in 2013 were tabulated and analyzed in order to allow a different view of performance, trying to qualify the results achieved by the segments of teachers, specialists, masters and doctors. As a result we can say that the courses better evaluated are offered by public institutions of higher education. And when the predominance of teachers with $\mathrm{PhD}$ training occurs, there is a tendency of the course to be carefully evaluated.
\end{abstract}

Keywords: Assessment. ENADE. Teaching. 


\section{INTRODUÇÃO}

A Engenharia de Produção (EP) iniciou-se em meados do século XX como uma evolução das demandas industriais, principalmente, no que tange à solução dos problemas nos processos fabris. De acordo com LEME (1983), no Brasil, sua origem deu-se na década de cinquenta do século XX, quando a Escola Politécnica da Universidade de São Paulo passou a oferecer o primeiro curso de EP.

Desde o seu surgimento, o número de cursos existentes vem aumentando consideravelmente. Segundo OLIVEIRA et al. (2005), "a partir de 1998 houve um crescimento vertiginoso do número de cursos de Engenharia de Produção no Brasil, passando de dos trinta e oito registrados em 1997 para aproximadamente duzentos cursos em 2005, registrando-se a criação em torno de quase vinte cursos por ano”. Uma consulta ao sistema eMEC aponta que, em julho de 2013, já se registram 585 cursos de Engenharia de Produção em atividade no Brasil.

Essa crescente oferta de cursos de Engenharia de Produção no Brasil exige a cada dia mais controle e dedicação por parte das instituições. Assim, a avaliação do curso ofertado nas universidades está em um processo constante de aperfeiçoamento, visando adequar às diversas faculdades e certificar que as mesmas ofereçam uma formação de qualidade para o corpo discente. Como uma das estratégias, o governo implementou, em 2004, o Sistema Nacional de Avaliação da Educação Superior (SINAES). A avaliação deveria contemplar a análise global e integrada das estruturas, formação do corpo docente, compromisso social, atividades, finalidades e responsabilidades sociais das IES e dos cursos a ela vinculados. Assim, o SINAES propõe-se a avaliar três pilares da IES: avaliação institucional, avaliação de cursos e avaliação de desempenho de estudantes (ENADE).

Quanto ao ENADE é um componente curricular obrigatório aplicado trienalmente aos ingressantes e concluintes do curso, a fim de acompanhar o processo de desempenho e de aprendizagem acadêmica dos estudantes em relação aos conteúdos programáticos propostos nas diretrizes curriculares dos respectivos cursos de graduação.

O Enade é o instrumento de avaliação que oportuniza um maior controle do perfil dos egressos das instituições de ensino, uma forma do MEC verificar se os egressos possuem as competências, habilidades e domínio de conhecimentos necessários para o exercício da profissão e da cidadania. Os resultados possibilitam aprimorar o processo de ensino- 
aprendizagem e o ambiente acadêmico dos cursos de graduação, formando profissionais capazes de responder às demandas sociais brasileiras.

A cada dia as demandas sociais tem exigido um profissional do ensino mais qualificado em relação ao saber ensinar, com capacidade de lidar com novas metodologias. Um novo perfil de docente é demandado, se exigindo que seja reflexivo e que atue como pesquisador de sua própria prática, que tenha consciência de sua ação educativa como estratégia de formação de profissionais e reconheça que o trabalho docente é muito mais do que repetir aquilo que se aprende nos livros.

Essa capacidade de reflexão tende a se tornar mais intensa a medida que o docente eleva sua formação, deixando de ser apenas um graduado, ao obter uma especialização, um mestrado e por fim, um doutorado. É justamente sobre este argumento que se posiciona o objetivo deste trabalho que é o de investigar se as instituições que empregam doutores, profissionais mais reflexivos, em seu quadro de docentes tendem a ter um desempenho melhor no exame nacional de desempenho estudantil.

\section{MATERIAIS E MÉTODOS}

Quantos aos meios, a primeira etapa foi bibliográfica se implementou através de artigos, livros, manuais e editais publicados das provas do ENADE, anais de congressos relacionados à educação em Engenharia, periódicos e site da ABEPRO.

Vergara (2005) afirma que a pesquisa bibliográfica é o estudo sistematizado desenvolvido a partir de materiais publicados em livros, revistas, jornais e redes eletrônicas, isto é, material acessível ao público em geral. Ganga (2012) acrescenta, ainda, que esse tipo de pesquisa procura explicar um problema a partir das referências teóricas publicadas em documentos, e que podem ser utilizada como parte da pesquisa descritiva.

Classificou-se a segunda etapa como documental, tendo em vista que foram analisados os resultados obtidos pelos alunos e instituições no ENADE aplicado em 2011, captados através do site do INEP.

Silva et al. (2009) explicam que a pesquisa bibliográfica e a pesquisa documental são distintas e que a diferença encontra-se na natureza das fontes, enquanto a bibliográfica remete a contribuições de vários autores, atentando a fontes secundárias. Em contraponto, a pesquisa documental recorre a documentos que não receberam tratamentos, ou seja, fonte primária. 
Os dados referentes aos resultados do ENADE do grupo VI de 2011 divulgados em 2013 foram tabulados e analisados de modo a se permitir uma diferente visão do desempenho não a nível de instituição, mas a nível de qualificar os resultados alcançados pelos segmentos de docentes, especialistas, mestres e doutores.

\section{REVISÃO DA LITERATURA}

O Exame Nacional de Desempenho dos Estudantes (ENADE) é uma prova que avalia periodicamente os conhecimentos dos egressos dos cursos de graduação. Já em relação aos ingressos cabe a participação de apenas da prova geral de conhecimentos ou apresentarem o comprovante de participação em edições anteriores do Exame Nacional do Ensino Médio (ENEM) para serem dispensados da participação no ENADE.

O SINAES propõe no manual do exame de 2011 que o ENADE tenha como objetivo:

"[...] o acompanhamento do processo de aprendizagem e do desempenho acadêmico dos estudantes em relação aos conteúdos programáticos previstos nas diretrizes curriculares do respectivo curso de graduação, suas habilidades para ajustamento às exigências decorrentes da evolução do conhecimento e suas competências para compreender temas exteriores ao âmbito específico de sua profissão, ligados à realidade brasileira e mundial e a outras áreas do conhecimento" (SINAES, 2011).

Os resultados do exame irão gerar dados de cada IES, categoria administrativa, organização acadêmica e região geográfica do Brasil. Dessa maneira, será formada uma base para referenciais que permitam a definição de ações voltadas à melhoria da qualidade dos cursos de graduação por parte de professores, técnicos, dirigentes e autoridades educacionais (SINAES, 2011).

O curso de Engenharia de Produção, que é a base dessa pesquisa, está inserida na área de Engenharia-Grupo VI, conforme destacado acima. De acordo com o SINAES (2011), este grupo é composto ainda pelos seguintes cursos: Engenharia de Produção Mecânica, Engenharia de Produção Elétrica, Engenharia de Produção Química, Engenharia de Produção Têxtil, Engenharia de Produção de Materiais e Engenharia de Produção Civil. Ou seja, é composta pela Engenharia de Produção plena e pelas suas "ênfases".

A prova de avaliação é composta por duas partes, sendo uma referente à formação geral do estudante - que é comum a todos os cursos de todas as áreas de conhecimento - e outra referente ao conhecimento específico adquirido ao longo de sua formação. 
Se por um lado existe se exige, por parte dos egressos, o domínio de determinadas competências e habilidades, de outro se posiciona o processo ensino aprendizagem, tendo os docentes como principal motivador e disseminador dos conteúdos formacionais.

No que se refere ao corpo docente da formação de Engenheiros, Silva e Cecílio (2007) fazem críticas em relação ao modelo de ensino utilizado. Na visão deles, há engenheiros que se "tornam professores" e ensinam o que sabem fazer; de outra há, professores que "ensinam" o que não fazem na prática. Uns ensinam em decorrência de sua formação e exercício de sua profissão, porém, às vezes, sem o reconhecimento ou a intencionalidade da dimensão pedagógica do trabalho docente. Outros transmitem e "ensinam" a teoria, muitas vezes sem as conexões com a prática.

A dissociação teoria e prática dificulta o processo de ensino-aprendizagem, além de acarretar insatisfações de alunos e professores e comprometer os resultados de suas ações. Importa que haja professores-formadores, que tenham domínio profissional e científico em relação ao que se propõem a fazer, que sejam reflexivos e atuem como pesquisadores de sua própria prática, que tenham consciência de sua ação educativa como estratégia de formação de profissionais e reconheçam que o trabalho docente é muito mais do que repetir aquilo que aprenderam nos cursos de formação inicial. Isso significa que precisam de uma formação pedagógica que os habilite a enfrentar uma sala de aula e, nela, desenvolver a condição de um mediador entre os alunos e a realidade. ( SILVA e CECÍLIO, 2007)

Oliveira et al. (2012) destacam, ainda, o baixo número de matriculados nos cursos de mestrado e doutorado da área de Engenharia. O percentual de doutores que atuam nos cursos de Engenharia corresponde a cerca da metade do verificado nos países da OCDE (Organization for Economic Co-operation and Development). Os países do BRICs (Brasil, Rússia, Índia e China), na média, publicam bem menos do que os países da OCDE, exceto a China, que só publica menos do que os Estados Unidos. Dentre os BRICs, o Brasil é o país que menos publica artigos na área da tecnologia, e isto também pode ser reflexo do baixo número de matrículas nos cursos de Mestrado e Doutorado no Brasil.

A figura 1 ilustra o percentual de titulação dos docentes que lecionam para cursos de tecnologia. 


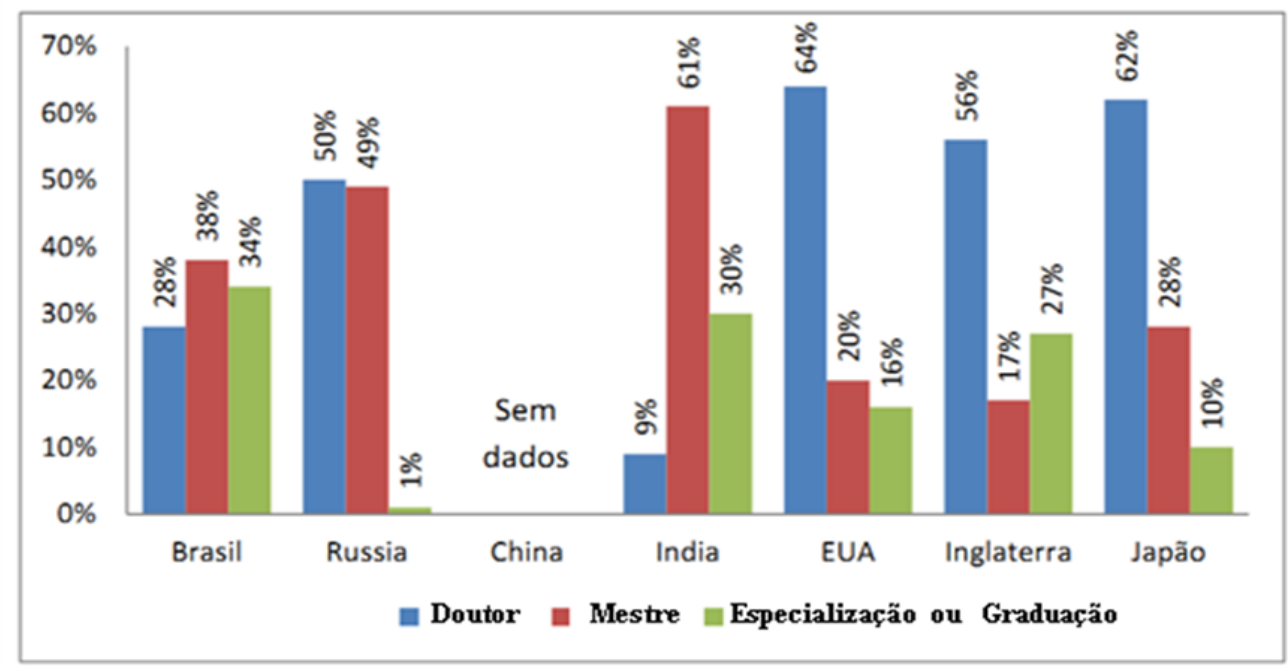

Figura 1 Percentual de titulação dos Docentes dos cursos da área de Tecnologia Fonte: Oliveira et al. (2012)

Nota-se, assim, que, dentre os países, o Brasil possui o maior percentual de docentes com apenas Graduação / Especialização. Além disso, apresenta um menor número de mestrandos e doutorandos na área de tecnologia.

\section{RESULTADOS E DISCUSSÃO}

O presente estudo restringiu-se a análise das planilhas do Grupo VI do ano de 2011, o qual está inserido a Engenharia de Produção e suas ênfases. De acordo com a Planilha de resultados (INEP, 2013) foram avaliadas neste ano um total de 215 Instituições de Ensino Superior (IES) que oferecem o curso. Em relação à localização dessas faculdades, o gráfico 1 ilustra a divisão geográfica desses cursos no território brasileiro.

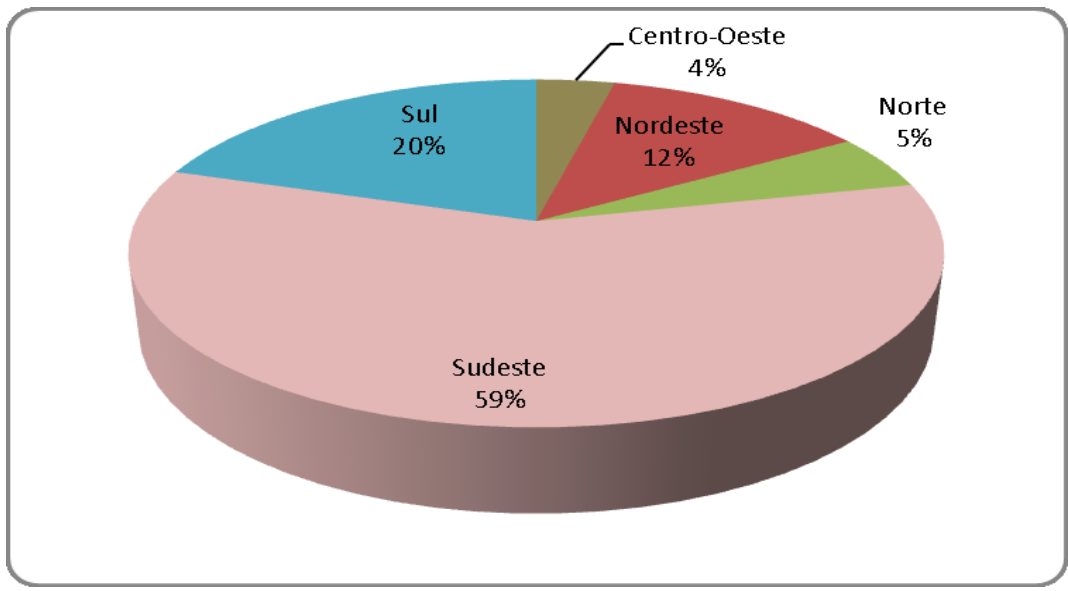

Gráfico 1 Divisão dos cursos analisados por regiões Fonte: Autora. 
Sob uma percepção inicial é notório que o maior percentual dos cursos $(59 \%)$ de Engenharia de Produção encontram-se na Região Sudeste do país. Este fato pode ser explicado em função dessa região englobar o estado pioneiro do curso, São Paulo, além do mesmo possuir maior PIB e população.

É perceptível também que existe uma distribuição desigual entre as regiões do país, sendo apresentado dessa forma um déficit de cursos desse segmento da Engenharia nas regiões Centro-oeste e Norte.

A tabela 1 ilustra o quantitativo de instituições públicas e privadas que cada região do Brasil está ofertando do curso de Engenharia de Produção, além de mostrar o quantitativo que cada região possui de faculdades públicas e privadas.

Tabela 1 Distinção entre públicas e privadas nas regiões do Brasil

\begin{tabular}{|l|c|c|}
\hline \multicolumn{1}{|c|}{ Regiões } & Privada & Pública \\
\hline Sudeste & 102 & 24 \\
\hline Sul & 29 & 14 \\
\hline Nordeste & 15 & 11 \\
\hline Norte & 6 & 6 \\
\hline Centro- Oeste & 5 & 3 \\
\hline Total & $\mathbf{1 5 7}$ & $\mathbf{5 8}$ \\
\hline
\end{tabular}

Fonte: Autora.

Observa-se que aproximadamente $74 \%$ das faculdades são privadas. Tal resultado pode ser justificado no fato do setor privado, em função do destaque que o curso obteve nos últimos anos, ter investido mais na oferta de cursos desse segmento da Engenharia para atrair novos alunos para sua instituição. Em contraponto as instituições públicas investem, em menor proporção, por terem como foco principal a manutenção dos cursos já existentes antes de criarem novos cursos e abrir mais vagas.

A análise da região Sudeste, tabela 1, aponta que o número de instituições privadas que oferecem EP é cerca de quatro vezes maior do que o número de instituições públicas. Tal resultado, conforme já mencionado, pode ser justificado pela demanda que essa região tem por Engenheiros, nessa proporção as faculdades tendem aumentar o número de cursos ofertados a fim de suprir essa carência de profissionais e atender a demanda de alunos interessados em cursar esse segmento da Engenharia. 
Outro fator relevante, em relação à região Norte, é que apresenta o mesmo quantitativo de instituições públicas e privadas que ofertam o curso de EP. Isso pode ser justificado pelas funções do profissional de Engenharia de Produção possivelmente não estarem muito claras tanto para as empresas da região quanto para os ingressantes / interessados no curso. Assim o número de IES privadas que estão ofertando o curso ainda não ultrapassou às públicas, conforme observado nas demais regiões.

O resultado, no que se refere à região Centro-Oeste, é similar ao apontado no estudo realizado por Faé e Ribeiro (2005). Os autores destacaram também que a oferta de cursos é insuficiente principalmente em função da vertente agroindústria, um dos fatores relevantes para a composição do PIB da região Centro-Oeste, além de ser uma importante modalidade a ser desenvolvida no âmbito da Engenharia de Produção.

No que se refere à infraestrutura, um dos requisitos também avaliados nesse processo de certificação, o Gráfico 2 representa esse cenário de acordo com as regiões do país.

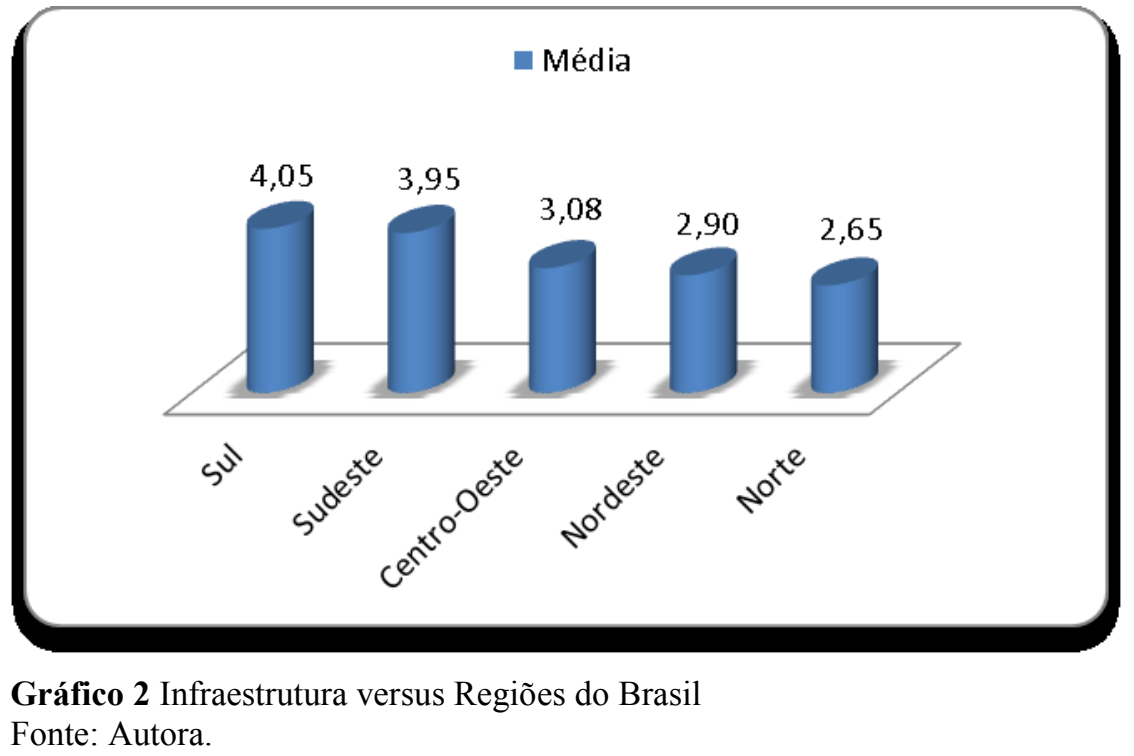

Para o cálculo do gráfico 2 não foram incluidas 7 faculdades que por diferentes motivos apresentaram nota 0 nesse item; sejam estes cursos que ainda não foram reconhecidos e outros que estão Sem Conceito (SC). Em função de tal fato, o total avaliado no item infraestrutura foram de 208 instituições.

Vale destacar, que as notas da avaliação estão na faixa de 1 a 5 e que nesse item foi questionado a infra-estrutura, especialmente a de ensino e de pesquisa, biblioteca, recursos de informação e comunicação. 
Apresentando uma média de 4,05 a região que oferece a melhor infraestrutura para os alunos são as da região Sul, porém vale destacar que a região Sudeste obeteve uma nota apenas 0,10 menor que a região Sul. Em função da insignificante diferença pode-se considerar que a região Sudeste além de ter o maior quantitativo de IES, esta possue também ótimas avaliações no que se refere a infraestrutura.

Outro ponto a se destacar é que apesar da região Centro-Oeste possuir o menor quantitativo de cursos, a mesma encontra-se em $3^{\circ}$ lugar na média da infraestrutura por Regiões. Em outros termos, apesar do quantitativo ser baixo, as IES que ofertam o curso a fazem com boas condições para os discentes.

Quando se faz a distribuição da infraestrutura por setor público e privado encontramos como resultado que as IES públicas possuem uma média de 2,94 ficando abaixo da média das privadas que é de 4,03. Isso se dá em função dos alunos das privadas por estarem pagando pela formação exigirem que a instituição proporcionem melhores instalações e infraestrutura; em contrapartida, apesar dos alunos das públicas terem o mesmo anseio em decorrência de questões burocráticas demoram a ser atendidos.

A formação e a qualidade do corpo docente também pode ser um fator a ser considerado para a justificativa do conceito alcançado no ENADE 2011 pelas instituições. Assim, o Gráfico 4 apresenta o quantitativo de professores de acordo com o título e com o conceito que as instituições que lecionam obtiveram no exame.

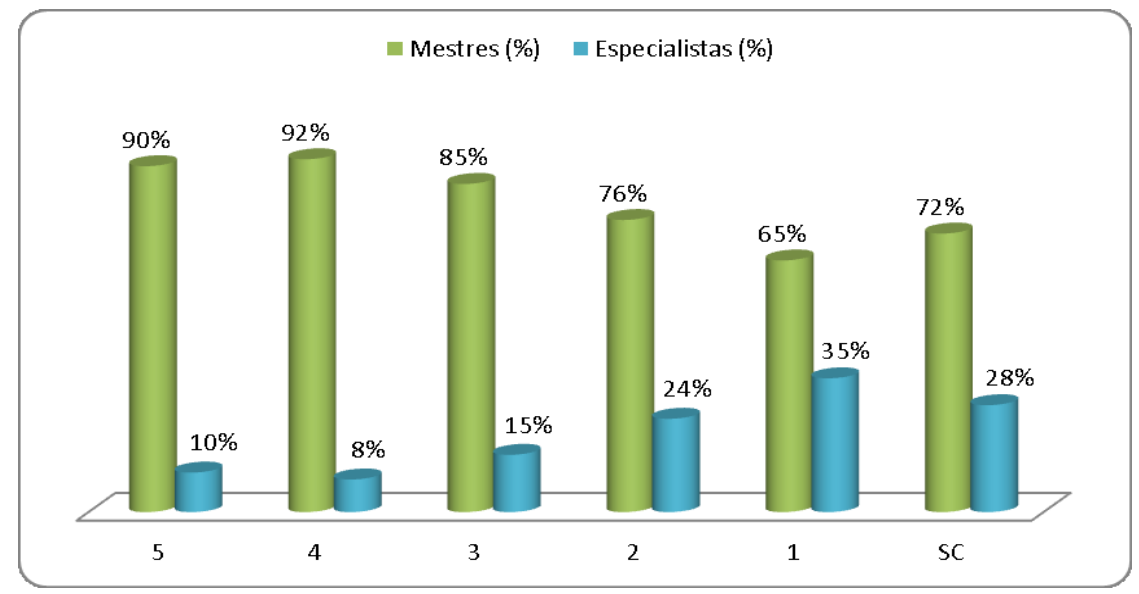

Gráfico 3 Formação dos docentes versus conceito no ENADE Fonte: Autora.

Destaca-se que todas as faixas apresentaram um percentual bom em relação ao quantitativo de professores que possuem o titulo de Mestres; porém o conceito "1", faixa mais 
baixa, obteve o menor percentual. Ressalta-se também que percentual de docentes que possuem apenas uma especialização é inversamente proporcional ao conceito alcançado no ENADE pelas instituições, em outros termos, conforme o conceito decresceu, o percentual de especialistas foi maior.

Tais análises anteriores podem ser usadas como justificativa para afirmar que a formação do corpo docente, interfere na formação dos alunos, e em função disso as instituições que não possuem docentes qualificados, os discentes atingiram conceitos mais baixos.

No gráfico 5, foi inserido um novo nível de formação dos professores, o doutorado, para que seja possível uma análise mais apurada da relação da formação dos professores com o conceito do ENADE. Lembrando que para um docente alcançar o nível do doutorado, na maioria dos casos, o mesmo já frequentou e concluiu um curso de mestrado. Dessa forma, no gráfico 5 foi utilizado o número de docentes que somente atingiram o nível do mestrado, ou seja, nessa amostra não estão inseridos os docentes que cursaram o mestrado e seguiram para o doutorado. Assim, como consequência a faixa intitulada como "somente doutores", estão contidos os profissionais que concluíram e possuem o título de Doutor, e não estando contabilizando os que possuam a formação "somente Mestres".

No gráfico 4 é possível perceber que, nas instituições privadas ocorre a predominância de professores mestres e especialistas. Nas instituições que alcançaram o conceito 5 no ENADE, ocorre a predominância de professores Doutores, $44 \%$ do total. Os resultados do ENADE tendem a ser piores a medida que reduz a relação entre Doutores e Mestres. E que a medida que se eleva o quantitativo de Especialistas se eleva para $25 \%$ e $35 \%$, o conceito alcançado se dá nas notas 2 e 1, respectivamente.

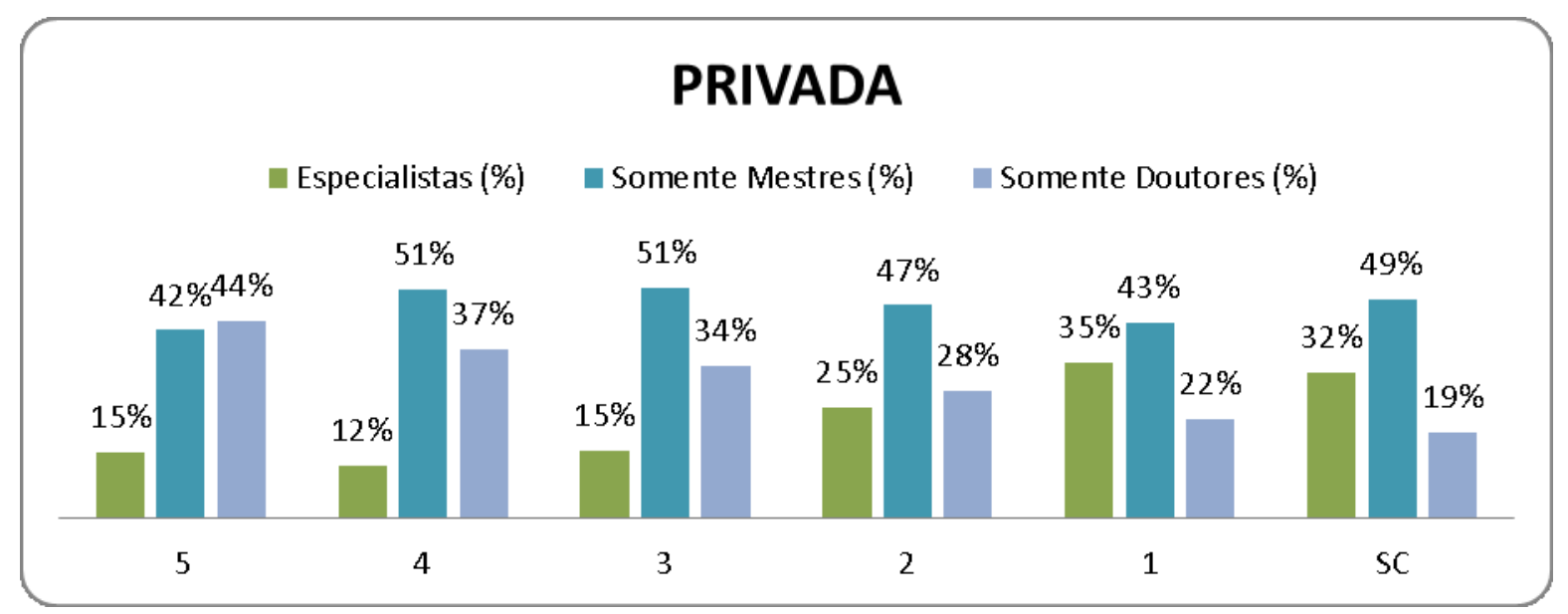


Gráfico 4 Comparação do corpo docente das IES privadas Fonte: Autora.

No gráfico 5 é possível perceber que, nas instituições públicas ocorre a predominância de professores Doutores. Nas instituições que alcançaram o conceito 5 no ENADE, ocorre a predominância de professores Doutores, $77 \%$ do total. Os resultados do ENADE tendem a ser piores a medida que se eleva a presença de mestres e especialistas. E que a medida que se eleva o quantitativo de Especialistas se eleva para $21 \%$ e $36 \%$, o conceito alcançado se dá nas notas 2 e 1 , respectivamente.

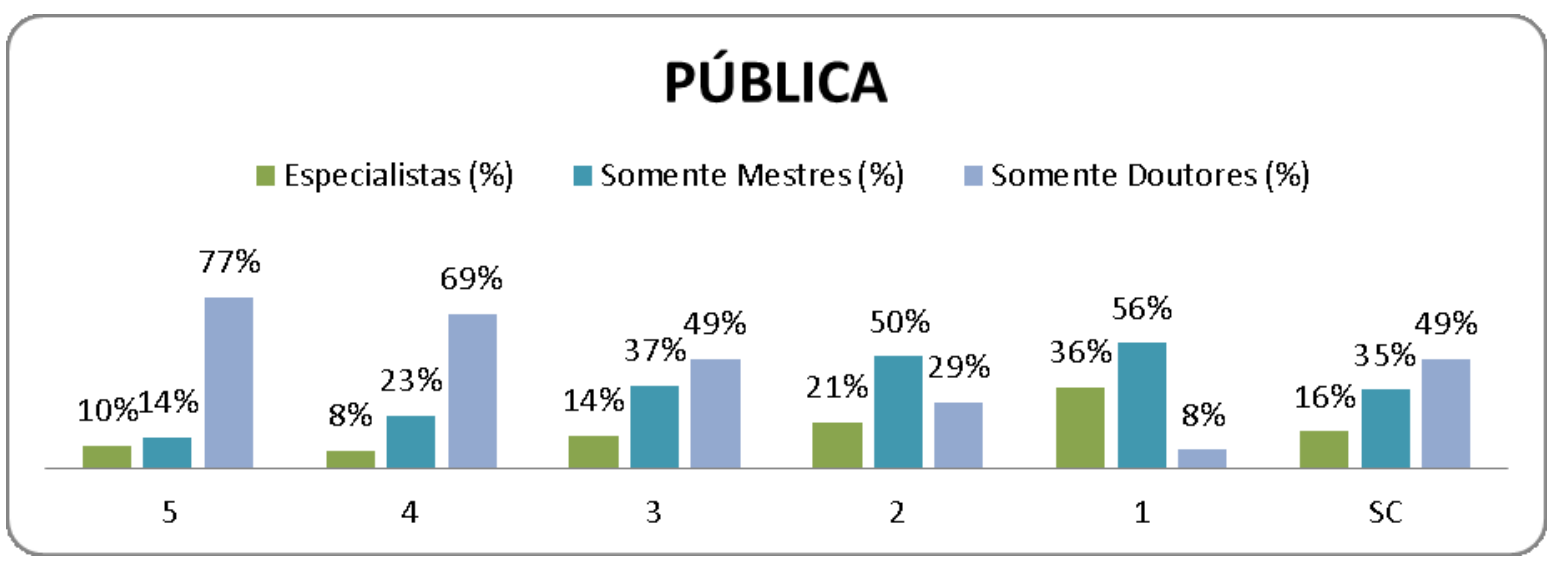

Gráfico 5 Comparação do corpo docente das IES públicas Fonte: Autora.

Observa-se na maior parte das faixas, de conceito do ENADE, que o quantitativo de Doutores que lecionam em instituições públicas é superior aos que lecionam nas privadas. Tal ponto justifica-se que esses docentes por possuírem um vínculo de exclusividade com a instituição possuem um tempo maior para a dedicação a pesquisa e projetos. Além disso, os professores da rede pública recebem incentivos em função as suas respectivas titulações.

Em contrapartida, o professor da rede particular, no geral, costuma ministrar aulas em mais de uma instituição, logo possuem menos tempo para se dedicarem a atividades extras. Além de que muitas vezes não recebem um incentivo por parte da instituição que atuam.

A diferença em relação ao quantitativo de doutores tende a ser maior entre as instituições privadas e públicas, tendo em vista a lei 12.863 sancionada em setembro de 2013 que passa a exigir o doutorado para os docentes das instituições federais que ofertam vagas do magistério superior.

Assim, como observado no Gráfico 4 e 5, quando realizada a análise de forma a dividir as instituições privadas e públicas o resultado encontrado foi o mesmo: a proporção de 
especialistas também tendeu a aumentar inversamente proporcional ao conceito do ENADE. Dessa maneira, independente da administração da instituição verificou-se o declínio de aproveitamento no exame.

A tabela 2 distribui as faculdades avaliadas em todo o Brasil em função do conceito que obtiveram na avaliação do ENADE.

Tabela 2 Distribuição das faculdades em função do conceito e região do Brasil

\begin{tabular}{|c|c|c|c|c|c|c|c|}
\hline \multirow{2}{*}{ Conceito } & \multicolumn{5}{|c|}{ Regiões } & \multirow{2}{*}{ Total } & \multirow{2}{*}{$\%$} \\
\hline & Centro-Oeste & Nordeste & Norte & Sudeste & Sul & & \\
\hline 5 & & & & 6 & 2 & 8 & $4 \%$ \\
\hline 4 & & 4 & 1 & 17 & 6 & 28 & $13 \%$ \\
\hline 3 & 1 & 7 & 4 & 15 & 16 & 43 & $20 \%$ \\
\hline 2 & 2 & 10 & 3 & 46 & 10 & 71 & $33 \%$ \\
\hline 1 & 1 & 2 & 2 & 6 & 1 & 12 & $6 \%$ \\
\hline SC & 4 & 3 & 2 & 36 & 8 & 53 & $25 \%$ \\
\hline Total & 8 & 26 & 12 & 126 & 43 & 215 & $100 \%$ \\
\hline
\end{tabular}

Fonte: Autora.

Pontuando que no grupo Sem Conceito (SC), do quadro acima, estão inseridas instituições que não inscreveram ingressantes que participaram do ENEM no ano de 2010.

Observa-se que $37 \%$ dos cursos encontram-se entre as faixas de conceito de 3 a 5 , faixa que é considerada de regular à excelente. Tal fato é preocupante visto que apenas 80 faculdades de um total de 215 encontram-se nesta faixa e a maior parte das instituições encontra-se no intervalo que é considerado insatisfatório.

As regiões Centro-oeste, Nordeste e Norte apesar de possuírem uma menor representação do total das instituições, aproximadamente $22 \%$, dentre esse grupo nenhuma instituição conseguiu atingir o conceito máximo do ENADE.

Ressalta-se que nas faixas "2", "1" e "SC" encontram-se um percentual de $63 \%$ do total; isto é um ponto crítico tendo em vista que essas são as faixas que refletem um menor aproveitamento dos discentes das instituições. E o fato de estar inserida na faixa 1 significa que a instituição está em verificação, podendo ser impedida de abrir novas turmas até a situação seja revista.

A tabela 3 indica o nome das oito instituições que obtiveram conceito 5 no ENADE de 2011. 
Tabela 3 Instituições que obtiveram conceito 5 no ENADE de 2011

\begin{tabular}{|l|c|c|}
\multicolumn{1}{|c|}{ IES } & Sigla UF & Região \\
\hline UNIVERSIDADE FEDERAL FLUMINENSE (UFF) & RJ & Sudeste \\
\hline UNIVERSIDADE FEDERAL DE JUIZ DE FORA (UFJF) & MG & Sudeste \\
\hline FUNDAÇÃO UNIVERSIDADE FEDERAL DO ABC (UFABC) & SP & Sudeste \\
\hline UNIVERSIDADE FEDERAL DO RIO DE JANEIRO (UFRJ) & RJ & Sudeste \\
\hline FACULDADE DE ADMINISTRAÇÃO DE EMPRESAS (FACAMP) * & SP & Sudeste \\
\hline UNIVERSIDADE FEDERAL DO ESPIRITO SANTO (UFES) & ES & Sudeste \\
\hline UNIVERSIDADE FEDERAL DE SANTA CATARINA (UFSC) & SC & Sul \\
\hline UNIVERSIDADE FEDERAL DO RIO GRANDE DO SUL (UFRGS) & RS & Sul \\
\hline
\end{tabular}

Legenda: *faculdade particular Fonte: Autora.

Das instituições que obtiveram conceito máximo, 75\% localiza-se no Sudeste, região a qual, segundo as análises anteriores, possui o maior número de instituições que ofertam o curso, além de ter a segunda melhor média das notas de infraestrutura. Tais fatos mencionados anteriormente podem ter contribuído para a formação de uma base mais sólida e consequentemente ter interferido nos resultados obtidos por essa região.

Ressalta-se também que na faixa cinco do conceito apenas a Faculdade de Administração de Empresas é privada. Ou seja, apesar desse setor possuir um quantitativo maior de cursos apenas uma conseguiu obter o conceito máximo no curso de Engenharia de Produção. Isso se deve em função dos alunos das IES púbicas terem como ingresso um vestibular mais rigoroso, fazendo com que os mesmos iniciem a trajetória acadêmica com uma base de conhecimento mais consistente. Em contrapartida, os ingressos das instituições particulares necessitam receber uma base antes dos conteúdos acadêmicos, o que faz com que o tempo de aprendizado seja maior e, em decorrência disso, o aproveitamento na prova do ENADE não seja tão eficiente.

O Gráfico 6 faz relação entre o conceito obtido no ENADE de acordo com o tipo de administração da instituição. 


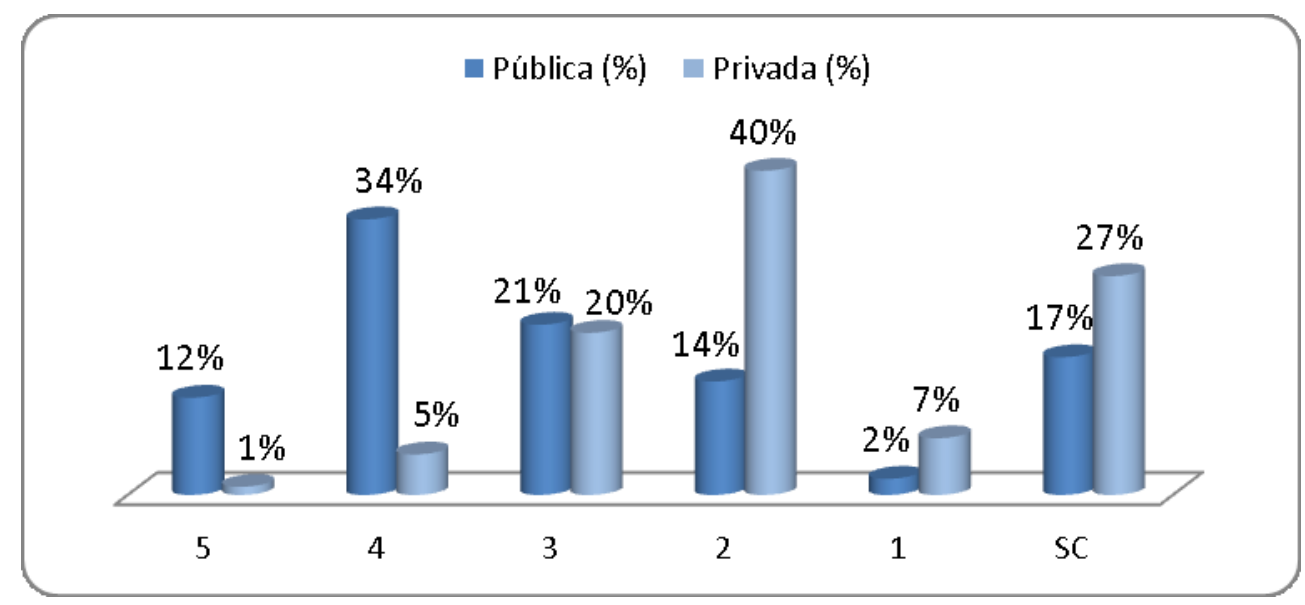

Gráfico 6 Conceito versus tipo de administração da IES Fonte: Autora.

Assim, por meio dos resultados apresentados no Gráfico 6 é possível apontar que na faixa dos conceitos 3,4 e 5 enquanto as públicas apresenta uma representatividade de $67 \%$ (39 das 58 instituições desse setor), as instituições privadas somente $26 \%$ do seu total encontram-se neste intervalo, apenas 40 das 159 instituições particulares avaliadas.

Dessa forma pode-se concluir que apesar das instituições privadas ofereceram uma melhor infraestrutura para os seus alunos, tal fator não tem relação com o desempenho dos alunos na prova do ENADE e no conceito geral divulgado pelo mesmo.

\section{CONSIDERAÇÕES FINAIS}

Os dados expostos reforçam que o aumento de cursos no país deve ser cauteloso, a sociedade espera que a qualidade da formação profissional ofertada adicionalmente se dê de forma qualitativa, não apenas quantitativa.

Apesar da educação, especificamente, de Engenharia de Produção ser o foco deste trabalho, vale destacar que a educação superior, no geral, tem por função desenvolver o potencial dos estudantes a partir de suas habilidades, levando-os a adquirir as competências profissionais necessárias para atuar em um cenário em constante transformação. Um ensino com déficit terá como uma das consequências a má qualificação dos mesmos e a oferta de profissionais despreparados.

A análise dos resultados do ENADE de 2011 permite concluir que, apesar do número de instituições que oferecem o curso de Engenharia de Produção, ter aumentado, tal acréscimo não se deu de forma qualitativa, sendo apenas quantitativo. Tendo em vista que dentre as 215 
instituições que foram avaliadas somente um percentual de $37 \%$ está dentro das faixas do ENADE que são consideradas satisfatórias (3,4 e 5).

Da mesma forma, é possível afirmar que os cursos mais bem avaliados são os ofertados pelas instituições públicas de ensino superior. E que quando ocorre a predominância de docentes com a formação de Doutor, há a tendência do curso ser bem avaliado. Os dados também apontam para uma relação do baixo conceito alcançado por um curso com a formação de professores, tendo como base a correlação entre a titulação dos professores e os resultados obtidos no ENADE pelas instituições. Observou-se ainda que nas faixas que possuem um número maior de especialistas, tanto na pública quanto na privada, o conceito foi inferior ao considerado bom para um funcionamento de uma IES.

\section{REFERÊNCIAS}

ANDRIOLA, Wagner Bandeira. Fatores institucionais associados aos resultados do Exame Nacional de Desempenho Estudantil (ENADE): Estudo dos cursos de graduação da Universidade Federal do Ceará (UFC).ISSN: 1696-4713. Revista Iberoamericana sobre Calidad, Eficacia y Cambio en Educación (2009)- Volumen 7, numero 1.

BRASIL. Lei $\mathbf{n}^{0}$. 9.131 de 24 de novembro de 1995. Altera dispositivos da Lei $\mathrm{n}^{0}$. 4.024, de 20 de dezembro de 1961 e dá outras providências. Brasília, 24 nov. 1995. Disponível em: $<$ http://www.planalto.gov.br/ccivil_03/leis/L9131.htm >. Acessado em: 25 de Abril de 2012.

BRITO, Márcia Regina F. de. O SINAES e o ENADE: da concepção à implantação. Avaliação (Campinas). 2008, vol.13, n.3, pp. 841-850. ISSN 1414-4077.

FAÉ, Cristhiano Stefani; RIBEIRO,José Luis Duarte. Um retrato da Engenharia de Produção no Brasil. Revista Gestão Industrial. v. 01, n. 03 : pp. 024-033, 2005. ISSN 18080448. 2005.

GANGA, Gilberto Miller Devós. Trabalho de conclusão de curso (TCC) na Engenharia de Produção: Um guia prático de conteúdo e forma. São Paulo: Atlas, 2012.

INEP. Resultados ENADE. $<$ http://portal.inep.gov.br/enade/resultados $>$. Acessado em: 10 de Janeiro de 2013.

INSTITUTO TEOTÔNIO VILELA. A crise das universidades públicas federais. Brasil Real - Cartas de conjuntura itv - n ${ }^{\circ} 97-$ julho/2012.

LEME, R. A. S. A história da engenharia de produção no Brasil. In: ENCONTRO NACIONAL DE ENGENHARIA DE PRODUÇÃO, 3, São Paulo. Anais. São Paulo, 1983. 
OLIVEIRA, V. F.; BARBOSA C. S. e CHRISPIM E. M. Cursos de Engenharia de Produção no Brasil: Crescimento e Projeções. Anais do XXV Encontro Nac. de Engenharia de Produção. Porto Alegre, RS, Brasil, 29 out a 01 de Novembro de 2005.

OLIVEIRA, Vanderli Fava de; ALMEIDA, Nival Nunes de; CARMO, Luiz Carlos Scavarda do.. Estudo comparativo da formação em engenharia: Brasil, BRICS e principais países da OCDE. COBENGE. XL Congresso Brasileiro de Educação em Engenharia. 2012.

SILVA, Jackson Ronie Sá; ALMEIDA, Cristóvão Domingos de; GUINDANI, Joel Felipe. Pesquisa documental: pistas teóricas e metodológicas. Revista Brasileira de História e Ciências Sociais. Ano I - Número I - Julho de 2009. ISSN: 2175-3423.

SILVA, Leandro Palis; CECÍLIO, Sálua. A mudança no modelo de ensino e de formação na Engenharia. Educação em Revista, Belo Horizonte, v. 45. p. 61-80. jun. 2007.

SINAES (Sistema Nacional de Avaliação de Educação Superior). Bases para uma nova proposta de avaliação da educação superior. 2003.

SINAES (Sistema Nacional de Avaliação de Educação Superior). Manual do Enade 2011. Brasília-DF, 18 de julho de 2011.

VASCONCELOS, Natália Veloso Caldas de.. Análise do Sistema de Avaliação da educação superior Brasileira. X Coloquio Internacional sobre Géstion Universitaria em América del Sur. Mar del Plata 8, 9 y 10 de Diciembre de 2010.

VERGARA, S. C. Métodos de pesquisa em administração. São Paulo: Atlas, 2005. 